\title{
Morbidity Profile of Children Admitted to a Regional Hospital of Hilly Region
}

\author{
Authors \\ Shikha Verma ${ }^{1}$, Ravinder Singh ${ }^{2 *}$ \\ ${ }^{1}$ Senior Resident, Department of Pediatrics Dr RPGMC Kangra H.P India \\ ${ }^{2}$ Medical Officer, Dermatology DR RKGMC Hamirpur H.P India \\ *Corresponding Author \\ Ravinder Singh
}

\begin{abstract}
Introduction: Annual child mortality rates in India have decreased between $1.7 \%$ and $2.3 \%$ in the last two decades. Still, the United Nations (UN) estimates that about 2.35 million (M) children died in India in 2005. This corresponds to over $20 \%$ of the world's under-five deaths, more than any other country. Children illness requires more frequent hospital care and younger children are more vulnerable to mortality. This study was, therefore, undertaken to evaluate the morbidity pattern in hospitalized children less than twelve years with all disease in a regional hospital of hilly region of India.

Methods: This was a hospital data based retrospective observational study carried out from August 2016 to July 2017. Hospitalized children were enrolled for the study and evaluated for morbid events leading to hospitalization.

Results: A total of 1068 patients were admitted in the pediatric ward of the hospital within the period under review. Out of these boys constituted $62.26 \%(n=665)$ boys and $37.73 \%(n=403)$ girls with boys to girls preponderance ratio of 1.65:1. The age group less than 5 years constituted the main chunk with total $784(73.40 \%)$ admissions. Seasonal variation in admission rate was also documented with maximum 378 (35.39\%) children admitted during hot weather season (July-Sept). Among morbidities respiratory tract infection was the leading cause with 300 (28.08\%) patients followed by patients with gastrointestinal diseases 214 (20.03\%). It was found that febrile seizures were quite prevalent in this region with 81 $(7.58 \%)$ admissions.

Conclusion: Research on morbidity is rather scanty. Yet it is very important and useful indicator of the health status of the people. The concept morbidity has more than one meaning. The findings indicate that there is a need to improve utilization of primary health care services including the vital MCH services for better child health and survival.
\end{abstract}

\section{Introduction}

India is a large country with huge variations in health indicators across states and districts of the country ${ }^{[1]}$. The Indian population consists of many communities with different cultures and habits and widely varying literacy rates. The morbidity and mortality pattern across India varies significantly as would be expected from the wide health and health determinant disparity spread across length and breadth of India ${ }^{[2,3]}$. Annual child mortality rates in India have decreased between $1.7 \%$ and $2.3 \%$ in the last two decades ${ }^{[4,5]}$. Still, the United 
Nations (UN) estimates that about 2.35 million (M) children died in India in 2005. This corresponds to over $20 \%$ of the world's under-five deaths, more than any other country ${ }^{[4,6]}$. Infectious diseases like diarrhoea, acute respiratory infections, malaria and whooping cough have been found to be the world's leading cause of morbidity and premature death especially in children in developing countries. $6.9 \%$ of deaths in children were attributed to respiratory infections, $2.2 \%$ to malarial fever and $2.0 \%$ to childhood diseases ${ }^{[7]}$. Two major infective illnesses in children are respiratory tract infection and diarrhoe ${ }^{[8,9]}$. In India, common morbidities among children are fever, acute respiratory infections, diarrhoea and malnutrition. The present study highlights the status of different types of morbidities in a regional hospital. This is the first study in Himachal Pradesh amongst children below 12 years of age with all causes of morbidity.

\section{Methodology}

Study Design and Period: It is a hospital data based retrospective study from August2016 to July 2017 for a period of one year.

Study Place: It was done at regional hospital Solan, Himachal Pradesh which caters population of district Solan and adjoining areas of district Sirmour and Shimla.

Inclusion Criteria: All children admitted in pediatric ward under 12 years of age. Exclusion Criteria: Infants less than one month of age who were admitted to SNCU.

Statistical Analysis: was done using Microsoft Office Excel@. The data entry on morbidity and mortality of all patients is routinely done in the medical records of respective wards of hospital. This data has information on socio-demographic, age, sex, diagnosis, treatment, condition at discharge and cause of death.

\section{Results}

Table 1: Demographic Profile of Admitted Children $(n=1068)$

\begin{tabular}{|c|c|c|}
\hline Gender & No. of Children & Total \\
\hline Male & $665(62.26 \%)$ & \multirow[b]{2}{*}{$1068(100 \%)$} \\
\hline Female & $403(37.73 \%)$ & \\
\hline \multicolumn{3}{|c|}{ Age Wise Distribution } \\
\hline$<1 y$ & $232(21.72 \%)$ & \multirow{3}{*}{$1068(100 \%)$} \\
\hline $1-5 y$ & $552(51.68 \%)$ & \\
\hline $6-12 y$ & $284(26.59 \%)$ & \\
\hline \multicolumn{3}{|c|}{ Area Wise Distribution } \\
\hline Solan & $660(61.79 \%)$ & \multirow{4}{*}{$1068(100 \%)$} \\
\hline Sirmour & $341(31.92 \%)$ & \\
\hline Shimla & $52(4.86 \%)$ & \\
\hline Other Places & $15(1.40 \%)$ & \\
\hline
\end{tabular}

A total of 1068 patients were admitted in the pediatric ward of the hospital within the period under review. Out of these $62.26 \%(n=665)$ were boys and $37.73 \%(n=403)$ were girls with boys to girls ratio of 1.65:1. Out of the total 1068 patients, $660(61.79 \%)$ children belonged to district Solan, $341(31.92 \%)$ children were from district Sirmour, $52(4.86 \%)$ were from district Shimla and only 15 $(1.40 \%)$ from other regions. $232(21.72 \%)$ were infants ( $<1$ year), $552(51.68 \%)$ between $(1-5$ years) and $284(26.59 \%)$ were between (6-12 years) of age. The age group less than 5 years constituted the main chunk with total 784 (73.40\%) admissions.

Table 2: Seasonal Variation of Children Admitted $(\mathrm{n}=1068)$

\begin{tabular}{|c|c|c|c|}
\hline Season & Month & No. of Children & Total \\
\hline \multirow{3}{*}{$\begin{array}{l}\text { Winter } \\
\text { (Dec-Jan) }\end{array}$} & Dec & $76(7.11 \%)$ & \multirow{3}{*}{$199(18.63 \%)$} \\
\hline & Jan & $64(5.99 \%)$ & \\
\hline & Feb & $59(5.92 \%)$ & \\
\hline \multirow{2}{*}{$\begin{array}{l}\text { Spring } \\
\text { (March- } \\
\text { April) }\end{array}$} & March & $93(8.70 \%)$ & \multirow[b]{2}{*}{$171(16.01 \%)$} \\
\hline & April & $78(7.30 \%)$ & \\
\hline \multirow{2}{*}{$\begin{array}{l}\text { Hot Dry } \\
\text { (May-June) }\end{array}$} & May & $83(7.77 \%)$ & \multirow[b]{2}{*}{$180(16.85 \%)$} \\
\hline & June & $97(9.08 \%)$ & \\
\hline \multirow{3}{*}{$\begin{array}{l}\text { Hot Wet } \\
\text { (July-Sept) }\end{array}$} & July & $136(12.73 \%)$ & \multirow{3}{*}{$378(35.39 \%)$} \\
\hline & August & $117(10.95 \%)$ & \\
\hline & Sept & $125(11.70 \%)$ & \\
\hline \multirow{2}{*}{$\begin{array}{l}\text { Autumn } \\
\text { (Oct-Nov) }\end{array}$} & Oct & $91(8.52 \%)$ & \multirow[b]{2}{*}{$140(13.10 \%)$} \\
\hline & Nov & $49(4.58 \%)$ & \\
\hline \multicolumn{2}{|c|}{ Total } & $1068(100 \%)$ & $1068(100 \%)$ \\
\hline
\end{tabular}

Seasonal variation in admission rate was also observed in this study. The maximum number of children 378(35.39\%) got admitted during hot wet 
season (July-Sept) followed by admissions 199 (18.63\%) in winter (Dec-Feb), 180 (16.85\%) in hot-dry season (May-June), 171 (16.02\%) in springs (March-April) and minimum admission 140(13.10\%) during autumn (Oct-Nov).

Table 3: Ten Leading Causes of Morbidities ( $n=$ 1068)

\begin{tabular}{|l|c|c|}
\hline Sr.No. & Morbidity & No. of Children \\
\hline 1. & Pneumonia & $117(10.95 \%)$ \\
\hline 2. & Diarrhoea & $116(10.86 \%)$ \\
\hline 3. & $\begin{array}{c}\text { Other Respiratory Tract } \\
\text { Infections }\end{array}$ & $183(17.13 \%)$ \\
\hline 4. & $\begin{array}{c}\text { Other Gastrointestinal } \\
\text { Diseases }\end{array}$ & $98(9.17 \%)$ \\
\hline 5. & Febrile Seizures & $81(7.58 \%)$ \\
\hline 6. & Seizures (Other) & $22(2.05 \%)$ \\
\hline 7. & Asthma & $39(3.65 \%)$ \\
\hline 8. & Poisoning & $18(1.68 \%)$ \\
\hline 9. & Snake bite & $9(0.84 \%)$ \\
\hline 10. & Others & $385(36.04 \%)$ \\
\hline & Total & $1068(100 \%)$ \\
\hline
\end{tabular}

Among morbidities respiratory tract infection was the leading cause with $300(28.08 \%)$ patients which included pneumonia $117(10.95 \%)$ and other respiratory tract infections $183(17.13 \%)$ followed by patients with gastrointestinal diseases 214 (20.03\%) comprised of diarrhoea patients 116 $(10.86 \%)$ and other gastro-intestinal manifestations 98 (9.17\%). It was found that febrile seizures were quite prevalent in this region with $81(7.58 \%)$ admissions. Remaining patients were of asthma 39(3.65\%), seizures $22(2.05 \%)$, poisoning $18(1.68 \%)$, snakebite $9(0.84 \%)$ and other system involvement like eye, ear, skin etc. $385(36.04 \%)$.

Table 4: Outcome of Children $(n=1068)$

\begin{tabular}{|l|c|}
\hline Discharge & $1050(98.31 \%)$ \\
\hline LAMA & $8(0.74 \%)$ \\
\hline Referred & $10(0.93 \%)$ \\
\hline Died & $0(0 \%)$ \\
\hline Total & $1068(100 \%)$ \\
\hline
\end{tabular}

Out of total patients $1050 \quad(98.31 \%)$ were discharged, $10(0.93 \%)$ were referred to higher institutes due to unavailability of diagnostic work up and ventilators and $8(0.74 \%)$ left against medical advice.

\section{Discussion}

This retrospective hospital based study evaluated one year of non-neonatal pediatric admissions at regional hospital. This analysis was limited to hospital admissions only, which did not include patients seen in the emergency and outpatients departments (OPD) per se. The present study shows that, more boys than girls were hospitalized with boys to girls preponderance ratio of $1.65: 1$. It is possible that parents have a higher acceptance of hospital admissions for their ill sons than for ill daughters. This is probably because of the cultural parental preference for male children .However, the probability of morbidity in females not being reported should also be considered. Similar finding of male predominance over females has been quoted by Lakshmi $^{[7]}$, by Bhansali ${ }^{[10]}$, Paramita $S^{[11]}$. In our study, it is observed that the highest number of morbidity among the children were in age group $(<5$ years) accounted $73.40 \%$ of all admissions. More boys than girls were admitted for all age groups. The infants are more prone for illnesses because of factors like decreasing immunity and associated malnutrition as a result of faulty weaning and in adequate food intake. This is in accordance with the observations by Lakshmi ${ }^{[7]}$ and Panda $\mathrm{P}^{[12]}$. Paramita $\mathrm{S}$ has reported malnutrition in under-fives having low birth weight and who have more than 2 siblings ${ }^{[11]}$. Among morbidities respiratory tract infection was the leading cause with 300 (28.08\%) patients which included pneumonia $117(10.95 \%)$ and other respiratory tract infections $183(17.13 \%)$ followed by patients with gastrointestinal diseases $214(20.03 \%)$ comprised of diarrhoea patients $116(10.86 \%)$ and other gastro-intestinal manifestations $98(9.17 \%)$. In brief together they account for almost half the burden of illnesses in admitted children. Venketesh et al also observed ARI to account for $42 \%$ of morbidity followed by diarrhoea $(13.6 \%)$ and skin disease $(11.8 \%)^{[13]}$. A study amongst under-fives in the Anganwadis also reported the above as most common cause of morbidity ${ }^{[14]}$. This indicates that the burden of these communicable diseases is still prevailing 
even at present. It was found that febrile seizures were quite prevalent in this region with $81(7.58 \%)$ admissions which is similar to the study done by Vanderberg BJ with prevalence of $5-10 \%$ in Indian kids ${ }^{[15]}$. Contrary to this finding, study by Shinnar S found that febrile seizures occur in 2 to $5 \%$ of children younger than age 5 years with a peak incidence in the second year of life ${ }^{[16]}$. There were $39(3.65 \%)$ admissions of children with asthma which is less than study done by Pal et $\mathrm{al}^{[17]}$. The reason could be patients of asthma are treated on OPD basis and admitted only during severe exacerbation. Present study shows that the rate of hospitalisation was significantly higher during the hot- wet season $378(35.39 \%)$ than the winter $199(18.63 \%)$, hot-dry180 (16.85\%), spring $171(16 \%)$ and autumn (13.10\%). This is the similar to findings from study done at Uttrakhand ${ }^{[18]}$. Further investigation is required to determine the cause of these trends.

\section{Strengths of the study}

This is the first study in the study area to highlight the morbidity pattern in hospitalized children of age below 12 years.

\section{Limitation of study}

This study was a hospital based study and hence does not represent the true rate of events for children in the general population.

\section{Conclusion}

The present study only highlights the status of different types of morbidities in a regional hospital. This is the first study in Himachal Pradesh amongst admitted children of pediatric age group with all causes of morbidity to highlights the morbidity pattern. The findings indicate that there is a need to improve utilization of primary health care services including the vital MCH services for better child health and survival. The regrettable side to the issue is that most of the morbidities are largely preventable by simple interventions like immunization, adequate nutrition promotion of hygienic practices, through proper health education to their parents. Community health workers should also be trained adequately.

\section{Funding: Nil}

Conflict of interest: None declared.

\section{Reference}

1. Annual Report 2010-11 Ministry of Health and Family Welfare. Department of Health and Family Welfare, 2011.

2. International Institute for Population Sciences (IIPS) National Family Health Survey (NFHS-2) 1998-99.International Institute for Population Sciences (IIPS), Mumbai, India, 1999.

3. Ministry of Home affairs SRS Bulletin. Sample Registration System, Registrar General, Ministry of Home affairs, Government of India, New Delhi. 2008;43:1

4. UN Population Division. World Population Prospects (2008 revision). [June 14, 2010]. http://esa.un.org/peps/peps_interpolateddata.htm.

5. Rajaratnam JK, Marcus JR, Flaxman AD, Wang H, Levin-Rector A, Dwyer L, et al. Neonatal , post neonatal, childhood, and under-5 mortality for 187 countries, 1970201: a systematic analysis of progress towards the Millenium Development Goal 4. Lancet 2010; 357:1988-2008.

6. UNICEF, WHO, Bank W UN Population Division. Child Survival and Health estimates developed by the Inter-agency Group for Child Mortality Estimation (IGME). [September 13, 2010]. http://www.childinfo.org/mortality.html.

7. Lakshmi J. A., Khyrunnisa Begum, Saraswathi G. \& Jamuna Prakash. Influence of Nutrition and Environment on Morbidity Profile of Indian Preschool Children. Mal J Nutr. 11(2): 121-132, 2005. 
8. Sudarshan MK, Parasuramalu BG, Gangaboriah. An epidemiological survey of diarrhoea among children in Karnataka region of Kaveri Basin. Indian Journal of Community Medicine, 1995, XX (1-4): 41 -45 .

9. Schachner LA, Hansen RG. Preface In: Pediatric Dermatology, Schachner LA, Hansen RG (eds). Edinburgh, Churchill Livingstone, 1995: IX.

10. Bhansali K.M., Mathur G.M., Sharma R. - A study of morbidity pattern in preschool children. Indian JPaediatrics. 46: 13-19, 1979.

11. Paramita S., Nina P., Benjamin A.I. Epidemiological correlates of undernutrition in Under-5 years childrenin an urban slum of Ludhiana. Health and Population: Perspectives and Issues. 33 (1), 1-9, 2010.

12. Panda P., Benjamin, A.I., \& Zachariah, P. - Health status of under-fives in a Ludhiana slum. Health and PopulationPerspectives and Issues. 16 (3\&4), 133141, 1993.

13. Venketesh S, Bansal RD. A longitudinal study of Morbidity among under-five Children in a Semi-Urban Area, Ind $\mathbf{J}$ Comm Med. 1986; 11:11-20.

14. Tondon BN, Sahai A, Balaji LN, Vardhan VA. Morbidity Pattern and Cause Specific Mortality during infancy in ICDS Projects J Trop Pediatr. 1987; 33:190-193.

15. Vander Berg BJ, Yerushalmy J. Studies on convulsive disorders in young children. I. The incidence of febrile and nonfebrile convulsions by age and other factors. Pediatr Res. 1969; 3:298-304.

16. Shinnar S. Febrile Seizures and Mesial Temporal Sclerosis. Epilepsy Curr. 2003; 3: 115-118.
17. Pal R, Dahal S, Pal S. Prevalence of bronchial asthma in Indian children. Indian J Community Med. 2009; 34(4):310- 316. doi:10.4103/0970-0218.58389.

18. Tyagi BB, Aswal RS, Haroon AS. Morbidity Patterns amongst Hospitalized Patients in a Secondary Care Hospital of Dehradun, Uttarakhand State, India. J Gen Pract Med Diagn. 2015; 1:003. 